\title{
ASPECTOS PSICOLÓGICOS DE PACIENTES RECÉM INSERIDOS AO TRATAMENTO HEMODIALÍTICO
}

\section{ARTIGO ORIGINAL}

MOREIRA, Joicy Dayanne Machado ${ }^{1}$

REIS, José de Arimatéia Rodrigues ${ }^{2}$

MOREIRA, Joicy Dayanne Machado. REIS, José de Arimatéia Rodrigues. Aspectos psicológicos de pacientes recém inseridos ao tratamento hemodialítico. Revista Científica Multidisciplinar Núcleo do Conhecimento. Ano 05, Ed. 10, Vol. 13, pp. 144163. Outubro de 2020. ISSN: 2448-0959, Link de acesso: https://www.nucleodoconhecimento.com.br/psicologia/tratamentohemodialitico

\section{RESUMO}

O objetivo principal desta pesquisa foi compreender os aspectos psicológicos de pacientes com IRC durante o período de inserção ao tratamento hemodialítico no decorrer do processo de internação. A metodologia empregada para este estudo foi de caráter qualitativo, tendo como estratégia de pesquisa um estudo de casos múltiplos. Participaram desta pesquisa 06 pacientes internados que estavam iniciando o tratamento hemodialítico em um hospital de referência em saúde renal no estado do Pará. A coleta de dados foi realizada a partir do acompanhamento psicológico dos pacientes, da observação participante, registro em diários de campo e análise documental (levantamento de prontuários). Os resultados nos indicam que os

\footnotetext{
${ }^{1}$ Psicóloga Especialista em Atenção à Saúde Renal - UEPA. Bacharel em PsicologiaUFPA.

2 Orientador. Doutorado em andamento em Programa de Pós-Graduação em Psicologia - PPGP. Mestrado em Psicologia. Especialização em Psicologia Hospitalar. Especialização em Saúde Coletiva. Graduação em Psicologia.
} 
participantes da pesquisa apresentam uma visão predominantemente negativa sobre a hemodiálise. Sinalizam que o início do tratamento hemodialítico atrelado a longa internação hospitalar, se configura como um fator que contribuí para o sofrimento psíquico do paciente. Podendo estar relacionado com a intensificação de queixas referentes a hospitalização, a inquietude e ao surgimento de sintomas psicológicos de ansiedade no aguardo de vaga ambulatorial e a intensificação de sintomatologia depressiva, principalmente quando o paciente percebe a ausência do suporte familiar e social. O estudo realizado contribuiu para a promoção da reflexão sobre a importância do acompanhamento psicológico em meio condições desfavoráveis decorrentes da inserção do paciente em hemodiálise durante o processo de internação.

Palavras-chave: Hemodiálise, diagnóstico, internação, hospitalização.

\section{INTRODUÇÃO}

A Doença Renal Crônica (DRC) ocorre de forma lenta, progressiva e irreversível. Ela pode ser classificada em 5 estágios, que abarcam um contínuo, entre a apresentação de um quadro assintomático até o estágio final, no qual o paciente precisa iniciar uma Terapia Renal Substitutiva (TRS). As modalidades de TRS disponíveis são: a hemodiálise (HD), a diálise peritoneal (DP) e o transplante renal.

Compreende-se, que algumas doenças como diabetes mellitus (DM), hipertensão arterial sistêmica (HAS) e glomerulonefrites e o aumento na expectativa de vida tem contribuído para o crescimento do número de casos de Doença Renal Crônica na atualidade. Cabe destacar que a falta de conhecimento sobre os fatores de prevenção e controle da doença, contribuem para que ela seja descoberta em estágios avançados, nos quais o paciente dificilmente pode escapar de ser mais um componente das estatísticas da população inserida em TRS.

Segundo o Censo realizado pela Sociedade Brasileira de Nefrologia, em 2018 existiam cerca de 133.000 pacientes em tratamento dialítico no Brasil, com cerca de $90 \%$ destes pacientes em hemodiálise. Este crescimento numérico tem elevado os 
custos para o Sistema Único de Saúde (SUS) que é responsável por $89 \%$ do financiamento deste tratamento (SZUSTER et al., 2012). É importante frisar que esta realidade não é exclusividade brasileira, trata-se de um recorte de um contexto mundial, no qual a IRC é concebida como uma importante questão de Saúde Pública (TEIXEIRA et al., 2014).

Segundo Pereira et al., (2016), A hemodiálise é modalidade mais prevalente de TRS. Ela é realizada em clínicas ou hospitais que ofereçam serviços especializados em nefrologia. Durante este procedimento o sangue é filtrado e libera o corpo de resíduos prejudiciais à saúde através do uso de uma máquina. Nesta modalidade de tratamento, o paciente recebe o suporte de uma equipe multiprofissional de saúde em ambiente hospitalar, a quantidade de sessões semanais pode variar segundo a condição clínica do paciente.

Além das sessões de hemodiálise, o paciente passa a realizar tratamento medicamentoso, controle de ingestão de líquidos e de ingestão alimentar, o que estende o tratamento para além das sessões de diálise. Muitos pacientes revelam dificuldades de lidar com estas restrições que afetam e influenciam sua qualidade de vida (CAVALCANTE et al., 2015).

Quando submetida ao tratamento de hemodiálise, a pessoa enfrenta diversas mudanças que excedem a perda da função renal. A rotina do tratamento implica em realizar em média 3 sessões de hemodiálise por semana, cada sessão tem a duração de cerca de 4 horas. $O$ estabelecimento desta nova rotina, muitas vezes envolve o deslocamento do paciente por longas horas até o centro de diálise, ou até mesmo implica em o paciente se mudar de seu local de origem até um lugar próximo do centro de diálise, visto que a realização dos procedimentos se torna indispensável para a manutenção de sua vida. Ou seja, a pessoa que adoece lida com diversos impactos nos âmbitos orgânicos, psicológicos e sociais. Como ressaltam Costa et al., (2014):

O afastamento do emprego, a redução da renda, o medo da morte, a perda de sua função/papel social. [...] A perda da percepção do corpo saudável, as alterações da imagem corporal (inchaço, alterações na 
pele, cateter na jugular ou na femoral, fístula) e as privações na vida social e no lazer.

A mudança brusca no modo de viver, o convívio com as limitações, o enfrentamento da hemodiálise como uma necessidade contínua e a possibilidade da morte, podem influenciar negativamente a qualidade de vida do paciente (SILVA et al., 2011). Estas inúmeras necessidades de readaptações decorrentes da perda da função renal nos possibilitam refletir sobre a reação emocional que vivenciamos diante de perdas significativas.

Todas as perdas significativas evocam em nós um processo transitório e doloroso, caracterizado pelo sofrimento e algum nível de desorganização psíquica. A esta fase damos o nome de luto. Vale ressaltar que o luto não está ligado unicamente a morte, ele pode acontecer por diversos motivos, pois, a dor da perda não se restringe apenas as situações de morte.

Uma das teorias mais conhecidas sobre o luto, foi desenvolvida por Elisabeth KublerRoss. A autora descreve cinco estágios experimentados por doentes diante da morte: negação, raiva, negociação, depressão, aceitação. Estes estágios, não são experimentados por todos os pacientes ou mesmo se apresentam nesta ordem, mas segundo esta teoria, em meio a perdas significavas uma pessoa apresentará pelo menos dois destes estágios (KUBLER-ROSS, 2019).

Ao discorrer sobre a reação emocional em meio a perdas, Kovács (2010) destaca alguns fatores que podem ser observados por terem interferência no processo de luto. Segundo ela, é necessário considerar fatores como, a fase de desenvolvimento em que a pessoa se encontra, se vive sozinho, se possui familiares ou uma rede de apoio, se possui condições econômicas, se se dedica ao cuidado de outras pessoas, enfim, a autora ressalta a importância de observar diversos fatores que podem favorecer ou dificultar a elaboração e ressignificação das perdas.

Vale ressaltar que, em meio a este processo de elaboração, pode ser que ocorra uma difícil espera, visto que, desde o momento de entrada no hospital até o encaminhamento ao centro de diálise, é comum que os pacientes permaneçam 
internados, dialisando no hospital enquanto aguardam vagas de hemodiálise, muitas vezes, já em condições de receber alta hospitalar. Entende-se que, neste primeiro momento, o paciente pode lidar de forma concomitante com questões relativas a seu adoecimento, tratamento, além dos fatores estressores da rotina hospitalar.

Além de considerar estes fatores, é válido destacar que a elaboração do luto não segue uma ordem específica, ou um tempo cronológico, e sim um tempo subjetivo, no qual, falar sobre a dor e obter um suporte psicológico adequado auxilia o fortalecimento de recursos internos, para que a pessoa dê conta da realidade o quanto possível e a partir deste fortalecimento, caminhe para a aceitação.

Diante deste contexto, esta pesquisa teve como objetivo: compreender os aspectos psicológicos do paciente com IRC durante o período de inserção ao tratamento hemodialítico no decorrer do processo de internação. Para isto, buscou-se compreender a percepção de pacientes recém-inseridos em tratamento hemodialítico sobre o diagnóstico e tratamento e descrever os sentimentos despertados no paciente referentes ao processo de adoecimento e internação.

\section{MÉTODO}

Esta pesquisa é pautada em uma abordagem qualitativa. Trata-se de um recorte de uma monografia elaborada na conclusão do curso de residência multiprofissional em saúde. Os resultados foram extraídos de um estudo de casos múltiplos, sendo a coleta de dados efetuada através da realização e registro de atendimentos psicológicos ocorridos durante o período de internação dos pacientes em um hospital de referência em atenção em saúde renal na região norte do Brasil.

\subsection{PARTICIPANTES}

A amostragem deste estudo fora composta de 6 (seis) participantes que iniciaram o tratamento hemodialítico na referida instituição. Quatro participantes eram do sexo feminino e dois participantes eram do sexo masculino. Com faixa etária entre 23 e 54 anos. 


\subsection{ACOMPANHAMENTO PSICOLÓGICO}

O contato inicial com os participantes ocorreu a partir dos atendimentos de rotina como psicóloga residente. Após a abordagem inicial e o estabelecimento de vínculo com os pacientes, eles foram convidados para participar da pesquisa e, após terem aceitado o convite e assinado o Termo de Consentimento Livre e Esclarecido (TCLE) deu-se início ao acompanhamento psicológico até o momento da alta hospitalar.

Os atendimentos ocorreram durante as sessões de hemodiálise e durante as visitas aos pacientes nas enfermarias, e foram gravados em áudio, conforme a autorização dos participantes da pesquisa, para garantir um resgate fidedigno dos trechos que se enquadravam nos objetivos do estudo.

\subsection{ANÁLISE DOS DADOS}

A partir dos dados obtidos durante os atendimentos, utilizou-se recortes de trechos significativos que se relacionaram aos objetivos do estudo e, desta forma, se originaram as categorias de análise. A exploração dos eixos de cada categoria, possibilitou o surgimento de subcategorias que foram discutidas a partir da literatura acadêmica.

\section{RESULTADOS E DISCUSSÃO}

A partir do acompanhamento dos casos, foram elaboradas duas categorias que se relacionam aos objetivos do estudo: 1) Percepções a respeito do tratamento. 2) Sentimentos experienciados durante período de diagnóstico e Internação. A seguir, iniciamos a discussão dos dados dos casos clínicos pela primeira categoria.

\subsection{PERCEPÇÕES A RESPEITO DO TRATAMENTO}

$\mathrm{Na}$ categoria 1, as principais características observadas nos pacientes acompanhados foram a grande expectativa relacionada a melhora da função renal, os impactos na percepção da imagem corporal, as dificuldades de adaptação ao tratamento e a Visão positiva a respeito da hemodiálise. Passamos à discussão dessas subcategorias: 


\subsubsection{EXPECTATIVA DE MELHORA DA FUNÇÃO RENAL}

Após os pacientes realizarem as primeiras sessões de hemodiálise, é comum que ocorra a diminuição dos sintomas de uremia e do desconforto causado pelo funcionamento renal prejudicado, desta forma, o paciente começa a se sentir como era antes de adoecer, quando seus rins ainda funcionavam de forma adequada. Neste momento, mesmo após serem oferecidos os esclarecimentos pertinentes ao quadro clínico, percebeu-se que alguns participantes traziam o discurso de crença na melhora da função renal, como se a hemodiálise fosse uma terapia de estímulo a função renal e não uma terapia substitutiva:

Monet: "A hemodiálise e um tratamento que ajuda muito, melhorou muito a minha vida porque ajuda a funcionar meu rim, né".

Frida: "E eu estou bastante melhor, bastante melhor, mesmo [...] eu já faço xixi, [...] se não fosse um tratamento desse eu já tinha até morrido. Eu sinto que o rim melhorou uns cinquenta por cento".

Anita: "Eu já melhorei muito desde quando cheguei aqui. Minhas pernas, meus braços, tá tudo desinchado [...] meu rim já tá melhor, só falta melhorar os exames pra eu ir pra casa e esquecer de tudo isso.

É interessante refletirmos que após as primeiras diálises, o paciente pode se deparar com sentimentos relacionados as frustrações e perdas decorrentes de ter a função renal prejudicada, visto que, a inserção neste tratamento, implica em diversas mudanças na vida do paciente, muitas delas bastante radicais, pois submetem o sujeito a condições limitantes e angustiantes, que ocasionam, além de perdas reais, muitas perdas simbólicas, nas quais o indivíduo passa a elaborar o luto do seu próprio corpo ao mesmo tempo em que deve se adaptar a sua nova condição física (SILVA et al., 2014)

Em meio a este período de elaboração, o discurso apresentado pelos participantes agrega alguns elementos relacionados à teoria de Kübler-Ross (2019). Segundo a autora, uma das fases comuns frente a perdas significativas é a negação. Esta fase é caracterizada pela dificuldade em acreditar que a perda realmente aconteceu e pela tentativa de se esquivar da situação vivenciada, devido a dor que ela causa. Trata-se 
de um mecanismo natural de autodefesa, pelo qual, ao negar o adoecimento, o paciente evita se implicar na realidade que o impele a um doloroso processo de elaboração.

$\mathrm{Na}$ busca pela autopreservação, esta resistência pode ser enxergada como uma forma de a pessoa que adoece defender sua totalidade, através de um funcionamento que a proteja momentaneamente de tomar consciência da experiência, da forma em que ela se apresenta.

\subsubsection{IMPACTOS NA PERCEPÇÃO DA IMAGEM CORPORAL}

No decorrer do tempo, é comum que o paciente hemodialítico sofra com as alterações corporais características da doença, como a descoloração da pele, a perda de peso ou as cicatrizes deixadas pelos acessos vasculares, exames e procedimentos, os quais impactam de forma significativa a identidade dessa população (COSTA; COUTINHO, 2014). Já no período de adaptação em hemodiálise, percebeu-se que, o uso dos cateteres causa grande impacto na percepção da imagem corporal dos participantes:

Pagu: "Agora só vai passar um cateter (Permicath) aqui no meu peito. Eu acho que é melhor [...] Não é nada legal ficar andando com essas antenas no pescoço (cateter duplo lúmen), chama muita atenção".

Frida: "Eu achei melhor que colocaram esse cateter na perna, porque aquele aqui em cima ficava aparecendo (cateter duplo lúmen). Aqui fica mais escondido".

Monet: "Esse negócio que colocam na gente (cateter) muda tudo. Agora tive até que mudar meu jeito de dormir pra não virar por cima. De vez em quando eu acordo e me ajeito [...] Demora pra acostumar porque isso não faz parte do corpo da gente, não é natural da gente "

Anita: "Eu acho isso difícil. Tiraram o cateter daqui, colocaram em cima [...]. Mandei fazer essa coisa no braço (FAV) e não funcionou. Aí, fizeram a outra aqui [...]. Quer dizer que para eu viver, vão furando meu corpo todinho?".

A sensação de ter um corpo estranho atrelado a seu corpo por tempo indeterminado, pode contribuir para alterações na percepção da autoimagem do paciente. Segundo 
o estudo de Nascimento (2013), os cateteres da hemodiálise ocasionam a sensação de vergonha frente a necessidade de o paciente andar entre seus pares, além de reclamações frequentes relacionadas ao desconforto causado pelos olhares curiosos. $O$ autor ressalta ainda que é comum que o paciente fale de si como um extraterrestre com "anteninhas" no pescoço.

Acerca este tema, em uma pesquisa realizada por Costa e Coutinho (2014), sobre as representações sociais dos pacientes em HD, percebeu-se que os participantes relacionavam o tratamento hemodialítico as alterações da imagem corporal decorrentes dele e definiam a hemodiálise como "levar furadas" para filtrar o sangue. O que nos faz refletir sobre o quanto a hemodiálise pode ser associada a dor e a tortura por quem está inserido na situação.

Em alguns momentos, percebe-se também a preocupação apresentada pelos participantes em relação as alterações corporais causadas pela Fistula Arteriovenosa. Foi observado que esta preocupação se manifesta inicialmente, a partir da observação de outros pacientes que já possuem uma FAV, nos quais se percebe a presença dos pseudoaneurismas que comprometem a parte estética do membro no qual a FAV é confeccionada:

Tarsila: "Tá marcado pra depois de amanhã pra fazer a fístula. Tô até preocupada, fica tão feio aquilo[...]. Eu tava vendo eles colocarem (ligarem) na mulher que faz diálise na mesma sala que eu. É uma agulhona, aquilo doí muito nas primeiras (diálises), ela falou".

Frida: "Eu só sei de uma coisa, eu não quero mais ser cortada, fizeram essa cirurgia no meu braço e eu já vi que fica feio depois... Esse tratamento e bom mais acaba com a gente".

A indicação da confecção da fístula é uma das primeiras marcas corporais experienciados durante o estágio dialítico. Sua presença, pode provocar outras alterações além dos pseudoaneurismas, como edemas e hematomas. Além disto, a FAV requer que o paciente desenvolva uma rotina de cuidados, que vão exigir desde a adaptação ao frêmito até novas configurações de rotinas de trabalho ou lazer, visto que os pacientes não podem impor esforço ao braço com a fístula sob o risco de comprometer o funcionamento do acesso (FRAZÃO et al, 2016). 
Apesar de a fístula exigir do paciente tantas implicações nos cuidados, observou-se neste estudo, que a preocupação apresentada pelos participantes, está relacionada principalmente as alterações na aparência do membro. Fato que corrobora a literatura, que relaciona alterações significativas de autoimagem decorrentes da IRC à fístula arteriovenosa (SILVA; SILVA; PEREIRA, 2016. OLIVEIRA; MARQUES, 2011; SPINOLA; GONÇALVES, 2012).

Para Silva et al (2014), as dificuldades do paciente dialítico em relação as mudanças no aspecto físico, podem estar relacionadas ao luto pela perda do corpo saudável, pelo qual o indivíduo passa a assumir um corpo com fragilidades, até então desconhecido. Estes mesmos autores ressaltam que a relação que o paciente dialítico estabelece com sua imagem pode levar a questionamentos existenciais relativos a importância de viver e de se relacionar com o outro, além de promover reflexões sobre a própria finitude.

\subsubsection{DIFICULDADES DE ADAPTAÇÃO AO TRATAMENTO}

Sabe-se também que a inserção ao tratamento hemodialítico pode causar estranhamentos de ordem mais prática, uma vez que ele é acompanhado por diversas restrições, dentre elas, as restrições hídricas:

Anita: "Às vezes a gente pede água, e elas (equipe) sabem que a gente tem problema de rim e falam que tem que beber pouco. Eu sei que tem que beber pouco, mas é difícil".

Di Cavalcanti: "É engraçado que parece que eu tinha pouca sede quando meu rim era bom, hoje tenho mais sede, mas não posso beber tanta água ".

Monet: "Eu fiquei só eu e Deus, com sede, sem beber nada o dia inteiro.

Psicóloga: Mas o senhor não precisa ficar sem beber nada o dia todo. Precisa ver a quantidade que o médico liberou, se for na quantidade certa, não tem problema.

Monet: Mas aquele pouquinho pra mim é mesmo que nada, parece que nem bebi". 
Percebe-se a partir desta pesquisa, que o ato de beber água, é tido como fator pouco valorizado antes do adoecimento, tal como é por parte de algumas pessoas que não possuem IRC, e passa a ser mais valorizado pelo paciente quando ele se encontra já em estágio dialítico, como sugere o estudo de Cavalcante et al., (2015).

Segundo a literatura, outro fator associado as dificuldades de adaptação ao tratamento são as restrições alimentares. Neste estudo, elas não foram evidenciadas, no entanto, é necessário considerar que os participantes permanecem em ambiente hospitalar, no qual seguem uma rotina alimentar diferenciada e não têm acesso a grupos alimentares comuns em seu cotidiano.

Durante o acompanhamento, existiram alguns episódios nos quais os participantes apresentaram pouca tolerância a dieta oferecida, porém estes incômodos pareceram se relacionar ao processo de hospitalização. Desta forma, entende-se que o paciente pode lidar de forma mais efetiva com os impactos das restrições alimentares após a alta, quando puder fazer suas próprias escolhas sobre que parece ou não ser mais adequado para o consumo de um paciente em diálise.

A necessidade de adaptação a esta nova forma de viver, impele o paciente a lidar com complicações que excedem as restrições hídricas e alimentares e se estendem a uma série de desconfortos e reverberações emocionais decorrentes das sessões de hemodiálise:

Anita: "Quando eu entro na sala, eu já me sinto triste porque não é fácil. A noite fico pensando, tem que dormir cedo e acordar cedo para ir lá, ser furada ".

Tarsila: "Eu imaginava que a pessoa ficava ali na máquina, mas não sabia que tinha aquele procedimento de dor, de tontura. [...] Eu só pensava assim: Ai, meu Deus! Ficar 4 horas sentada, mas não sabia que a pessoa sofria tanto".

Di Cavalcanti: "Fiquei com uma dor nas costas [...] Aquela cadeirinha é terrível".

Frida: "Passei mal de verdade, pensei que ia morrer (Episódio de hipoglicemia). Já pensou, toda a diálise isso..." 
Em outros momentos, os pacientes relatam incômodos referentes as manifestações clínicas da doença, enfatizando a sensação de fadiga apresentada após a diálise e a influência desta consequência do tratamento em suas atividades cotidianas:

Monet: "Quero andar, mas cadê as pernas? Nem tenho mais forças nas pernas. Vou fazer hemodiálise, quando subo, me sinto fraco [...] Fico pensando, quando eu for pra casa, como vou cuidar das minhas coisas".

Tarsila: "Hoje depois que subi, nem quis comer quase nada. Só merendei na diálise mesmo. Quando cheguei aqui, só dormi, não dei conta de fazer nada mais. Pareceu assim, que eu tinha levado uma surra".

Frida: "Até que eu fico bem na diálise, depois que termina que eu sinto muita fome. Subo bem, como, deito e durmo, porque vem uma sensação de cansaço, mas é só depois".

A respeito das falas apresentadas, percebe-se os impactos negativos causados pelas intercorrências no período em que os pacientes não estão habituados ao tratamento. Alguns pacientes toleram a diálise sem grandes impactos, outros, porém, apresentam mais intercorrências durante a sessão de HD ou sintomas como: cansaço, mal-estar, fadiga, fraqueza e náuseas após a diálise, fatores que podem apresentar impacto significativo nos níveis de qualidade de vida dos pacientes (SILVA et al, 2017).

A realidade das intercorrências durante as sessões de $\mathrm{HD}$ e dos impactos corporais após a dialise, compõe um universo que, com o tempo, grande parte dos pacientes aprendem a conviver. Podendo passar a perceber mais seu próprio corpo, sinalizando para a equipe quaisquer desconfortos durante as sessões de diálise e desenvolvendo suas estratégias para lidar com o período pós-diálise.

Apesar da realidade ser permeada por aspectos que contribuem para uma percepção negativa a respeito do tratamento, em algumas falas, os pacientes demonstraram um olhar mais positivo em relação a hemodiálise, como veremos a seguir:

\subsubsection{VISÃO POSITIVA EM RELAÇÃO AO TRATAMENTO}

A partir dos discursos dos participantes, observou-se uma consideração positiva em relação ao tratamento, relacionada a compreensão da importância da hemodiálise 
para a continuidade da vida, a possibilidade de adaptação ao tratamento e ao suporte oferecido pela equipe que atua em nefrologia.

Di Cavalcanti: "Se não fosse esse tratamento eu não estaria aqui hoje. [...] Eu agradeço por estar aqui. Agradeço a equipe que já me conhece, que cuida de mim".

Tarsila: "A hemodiálise não é fácil, mas e se ela não existisse?"

Pagu: "O Difícil não e nem o tratamento. O mais difícil e essa vaga... Se tivesse, eu já ia pra casa ".

Di Cavalcanti: "Nas primeiras (sessões) me dava até as coisas, eu pensava que ia desmaiar. Depois parece que melhorou mais, a gente vai se acostumando".

Ao longo dos acompanhamentos, percebeu-se que a visão positiva relacionada ao tratamento, pode estar relacionada as possibilidades dos participantes de lidar com a condição crônica, não no sentido de projetar sobre o tratamento uma visão romântica, mas de estabelecer uma tentativa de conviver com seu novo quadro de saúde. E, se por um lado, a negação pode impactar negativamente sobre a implicação, a aceitação, a favorece. A percepção positiva sobre o tratamento, pode levar à melhor adesão e a um maior bem-estar físico e psicológico dos pacientes (CASTRO et al., 2018).

Observou-se que os pacientes que estão iniciando o tratamento hemodialítico, apresentam uma visão predominantemente negativa sobre a hemodiálise. A inserção neste novo universo, evoca preocupações relacionadas as alterações na imagem corporal, as restrições as quais os participantes terão que se adaptar e aos efeitos adversos frequentes da diálise. Fatores que os atentam as modificações que serão realizadas em suas atividades cotidianas quando estiverem em tratamento dialítico ambulatorial.

\subsection{SENTIMENTOS EXPERIENCIADOS DURANTE PERÍODO DE DIAGNÓSTICO E INTERNAÇÃO}

Nesta categoria, também foram observadas algumas características predominantes nos discursos dos pacientes em acompanhamento, tais como, Abalo emocional frente 
a ausência de suporte social, Tristeza relacionada ao adoecimento e internação, Revolta relacionada ao adoecimento e Angústia relacionada as mudanças no estilo de vida após a alta hospitalar. Passamos à discussão desses pontos principais:

\subsubsection{ABALO EMOCIONAL RELACIONADO A AUSÊNCIA DE SUPORTE SOCIAL}

Enquanto aguardam a vaga de hemodiálise, percebeu-se que a ausência de familiares e amigos durante o período de internação, pode evocar reflexões sobre a importância da afetividade na vida dos pacientes, gerando até mesmo, percepções de discrepância entre a presença de pessoas significativas antes e após do adoecimento.

Tarsila: "Tô a quase 5 meses aqui...Tinha tantos amigos, agora cadê? Eu já ajudei tanta gente na minha vida e hoje na doença ninguém nem visita, ninguém liga[... ]Fico pensando assim, quando a pessoa morre sozinha deve ser muito triste".

Monet: "O rim não presta, perdi a vista, o coração tá ruim, não posso nem andar no corredor, [...] pior é que o pessoal (pacientes) só fala comigo lá na diálise, eles só cumprimenta, mas pelo menos fala. Aqui (isolamento) ninguém vem nem conversar comigo, porque pensam que vou passar alguma coisa pra eles".

Anita: "É como diz o povo: Uma mãe é pra cem filhos, mas cem filhos não é pra uma mãe[...] Eu criei eles sozinha, passei aperreio, mas não abandonei nenhum. [...] Só uma fica aqui comigo, os outros até pra ligar, só liga quando quer".

Bastos et al., (2016) definem o suporte social como a percepção de fazer parte de uma rede de afeto e de ajuda mútua. Esta percepção é fundamental para o enfrentamento de uma doença crônica. Logo, sua ausência, tende a contribuir para que o indivíduo se perceba mais despreparado para lidar com a situação vivenciada.

A definição destes autores, se relaciona aos resultados desta pesquisa, pois percebeu-se que o fato de o paciente não estar implicado em uma rede de apoio pode contribuir para o surgimento de sentimentos de menos valia e abandono, pois a ausência de familiares e amigos tem relação com o senso de estabilidade dos pacientes. 
Ao se perceberem sem este suporte, notou-se que alguns pacientes tendem a realizar movimentos de isolamento durante a internação, podendo, estes movimentos, estarem ligados a uma percepção negativa dos relacionamentos, como se os vínculos fossem frágeis e tolerassem apenas os momentos de bem-estar emocional, em detrimento dos momentos em que o outro precisa de afeto e cuidado.

\subsubsection{TRISTEZA RELACIONADA AO ADOECIMENTO E INTERNAÇÃO}

Durante as abordagens e atendimentos psicológicos no âmbito hospitalar, é compreensível e, até mesmo esperado que a tristeza se manifeste após o diagnóstico de uma doença crônica e também durante o período de inserção ao tratamento. A tristeza que permeia a relação inicial com a hemodiálise, é vivenciada juntamente com a dura constatação de sua necessidade. Pois, ao consumir uma quantidade a mais de líquidos, o corpo vai ficando edemaciado e aos poucos, o paciente vai percebendo a importância da diálise para a sua sobrevivência, assim como os riscos aos quais está submetido enquanto paciente dialítico.

Através do acompanhamento psicológico, foi possível perceber que a tristeza surgiu, em alguns casos, de forma duradoura e associada a outros sintomas, que aproximaram esta emoção a possibilidade de uma tristeza patológica ou de um disparador de sintomas psicológicos de ansiedade.

Monet: "Eu só tenho vontade de chorar [...] Eu já pedi pra Deus me levar, se não me curar que me leve logo. É melhor que viver nessa vida triste (choro)".

Anita: "Eu tô com uma tristeza muito grande, já não tô dormindo direito, não quero comer, nem fazer nada [...] tô ficando com medo por causa da minha depressão[...] quando tive crise, começou assim".

Tarsila: "Hoje na diálise, um menino passou muito mal. Ele tava do meu lado, gritava tanto que fiquei até nervosa. [...] É muito triste de se ver [...] Fiquei pensando, se um dia isso acontecer comigo [...]. Dá uma aflição o tempo todo, parece que um dia vai ser comigo, uma hora vai ser comigo"... 
As reverberações do adoecimento renal segundo Costa e Coutinho (2014), estão ligadas a maiores dúvidas, inseguranças, medo, angústia e sofrimento quanto a cura e à possibilidade de viver. Tais resultados sinalizam que o processo adaptativo ao tratamento coloca os participantes em um grau intenso de sofrimento psíquico, que podem contribuir para que o paciente perceba suas possibilidades de ajustamento como cristalizadas.

Vale ressaltar que, além de os participantes estarem se "adaptando" a conviver com a doença e começando a compreender a iminência da morte, passam também a perceber a falta de outras opções terapêuticas no momento, já que permanecem aguardando vaga de hemodiálise ambulatorial. Neste contexto, emoções como a tristeza, foram trazidas também em virtude dos impactos da internação hospitalar:

Monet: "Hoje veio aquela tristeza de novo, chorei demais, muito mesmo. Diz que homem não chora, Mentira! [...]. Minha velha de cabelinho branco (esposa), eu amo demais ela! Eu não esqueço nenhum segundo...".

Pagu: " Talvez eu me sinta melhor quando eu for pra casa. Por que aí, eu vou ter mais tempo pra sair, me distrair e fazer algumas coisas que eu fazia antes".

Anita: "Eu nunca senti tanta falta da minha casa, da minha cama, das minhas plantas, do meu cachorro, tadinho dele! (choro) [...] Dá uma tristeza saber que tudo meu tá se acabando".

Pagu: "Da uma tristeza só de pensar que ele (filho da paciente) tá pela casa de um e de outro... Já nem me importo se vou fazer esse tratamento ou não, só quero sair daqui”.

Tarsila: "Depender dos outros é muito difícil, muito difícil mesmo. Ainda mais aqui. A pessoa fica deitada nessa cama, vai pra diálise e volta, vai pra diálise e volta, vai pra diálise e volta... [...] Assim muito tempo internada, não é legal, não ".

Anita: "Fico pensando assim, como é a vida de um presidiário. Aqui cuidam da gente, a gente vai na área, conversa, assiste TV e já dá uma agonia... imagina quem fica numa cela. Só não fica doido mesmo se tiver a cabeça muito forte". 
O processo de hospitalização no qual os participantes estão implicados também causa grande impacto emocional, pois provoca mudanças relacionadas a ambiência do paciente e interferem diretamente em suas atividades cotidianas. Neste contexto, além dos sentimentos associados ao fato de estar doente, é comum que surjam aspectos psicológicos de angústia pelo afastamento de casa, da família, do trabalho, dos amigos, enfim, de sua configuração de vida anterior a internação.

É necessário frisar que, os aspectos emocionais podem ser experienciados de forma mais intensa quando a internação se prolonga. Entre os participantes da pesquisa, tivemos um tempo mínimo de 2 (dois) meses de internação e, na maioria dos casos, os pacientes eram considerados estáveis e aguardavam apenas as vagas de hemodiálise. Percebeu-se que esta longa espera poderia estar relacionada com um aumento do nível de inquietação dos pacientes e com a manifestação de sintomas psicológicos de ansiedade, voltados a perspectiva de receber uma boa notícia, como a tão esperada vaga de hemodiálise.

O discurso de angústia frente a demora para o surgimento da vaga ambulatorial, se torna mais denso e carregado de pesar, quando o paciente tem a consciência de que as vagas são liberadas através da criação de novos centros de hemodiálise, da ampliação do número de vagas nos centros existentes e a partir da disponibilidade de vagas nos centros após o transplante ou o óbito de outro paciente.

Tarsila: “... de pensar que a gente fica aqui, torcendo pra uma vaga e na realidade outra pessoa tem que morrer pra gente poder ir pra casa [...] Não bastasse tudo de ruim, agente ainda depende do pior dos outros".

De fato, se sabe que o ideal e que o paciente permaneça o menor período possível de tempo internado para que possa retornar a sua casa. No entanto, a gerência sobre as vagas de HD, não é de controle hospitalar, e sim de órgãos municipais e estaduais, que viabilizam as vagas conforme a fila de espera e disponibilidade em centros de diálise.

Além do fator ansiedade, cabe destacar que os pacientes Monet, Anita e Tarsila, apresentaram sintomatologia depressiva, que fora percebida como humor 
entristecido, discurso de menos valia, alterações no período de sono e vigília, falta de apetite, pouca implicação em tentativas de socialização e na realização de atividades básicas de autocuidado.

Estudos atuais apontam a depressão como a condição psiquiátrica mais presente em pacientes com IRC em estágio dialítico. O alto índice de sintomas depressivos neste público, Segundo Pop-Jordanova e Polenakovic (2012) ocorrem com maior frequência no período inicial da hemodiálise, quando os pacientes se encontram pouco adaptados à rotina e ao esquema terapêutico rigoroso, e no período final da hemodiálise, quando o declínio funcional e os sintomas crônicos, irreversíveis e incuráveis se agravam. Segundo os mesmos autores, é possível que a maior parte dos pacientes com IRC em estágio dialítico apresentem sintomas depressivos, mas em menos de $25 \%$ dos pacientes os sintomas podem ser considerados graves.

Com relação aos participantes da pesquisa, há de se considerar, que a rotina imposta pelo tratamento, atrelada a retirada da liberdade e individualidade da pessoa do ambiente hospitalar, podem ser potencializadoras tanto para o surgimento de sintomatologia depressiva, como para o surgimento desta inquietude em relação a vaga ambulatorial. Visto que, a alta hospitalar está ligada ao retorno do paciente ao seu convívio familiar e social e a possibilidade de viver sua vida de forma mais próxima ao que era antes do adoecimento.

\subsubsection{REVOLTA RELACIONADA AO ADOECIMENTO}

Surgiram entre os participantes discursos de revolta em relação ao tratamento, geralmente associados a compreensão de que terão que conviver com a doença e de que não existe nada que possa ser feito para reverter a situação:

Tarsila: "Eu tenho um rim policístico, é de família, quer dizer que um dia ia parar mesmo. Mas porque eu? Porque que eu que tenho que passar por isso. Já não basta tudo o que eu já passei e venho passando todos esses anos?". 
Monet: "Hoje eu nem queria descer porque eu tava bem. [...] O médico veio aqui e explicou que tem que fazer sempre [...] Precisar de uma máquina o tempo todo, isso lá é vida ".

Frida: "Eu não me conformo com essa situação (diálise), não me conformo mesmo".

Anita: "Gente é gente, máquina e máquina. Tá tudo errado nesse mundo! $"$.

Essa dificuldade em se conformar com a situação, Segundo Kubler-Ross, 2019, pode ser classificada como mais um estágio do luto, por ela denominado de Raiva. Nesta fase, é comum que ocorra a tomada consciência das perdas e das mudanças ocasionadas por elas, desta forma, a não aceitação do fato é canalizada através da emoção raiva.

Neste estágio, e comum que a pessoa enlutada se sinta injustiçada e que direcione esta raiva a um objeto, a outra pessoa ou a si próprio. Nos relatos obtidos, percebese, em sua maioria, um direcionamento voltado a máquina de hemodiálise e a sensação de dependência que ela proporciona.

\subsubsection{ANGÚSTIA RELACIONADA AS MUDANÇAS NO ESTILO DE VIDA APÓS A ALTA HOSPITALAR}

Durante a internação, os pacientes acabam por ficar alheios a vida que tinham antes da hospitalização, o que de certa forma, também os deixa distantes dos desafios que enfrentarão após a alta hospitalar. Este distanciamento, muitas vezes, os deixa angustiados, pois, ainda dentro do hospital, e possível refletir sobre as mudanças que deverão ser realizadas após a alta.

Tarsila: "São 3 irmãos, mas não posso contar com os outros dois. Minha mãe tem quase 80 anos e precisa descansar. [...]. Eu não sei como vai ser quando chegar em casa [...]. Agora vem as restrições também, que aqui a comida e controlada, com pouco sal. La fora é que nós vamos ver".

Di Cavalcanti: "Só fico pensando como vai ser, porque minha mãe trabalha e eu cuido da minha avó e trabalho a noite. Agora que eu vou 
fazer tratamento fora, vai ficar mais difícil, principalmente porque não sei quem vai cuidar da minha avó".

Pagu: "Queria só sair daqui e organizar as coisas logo. Ver o horário da diálise, antes de matricular o Davi na escola. Tenho que ver isso também".

Anita: "Fico pensando, se eu não puder mais fazer as coisas, limpar a casa, cuidar da roça. [...] Parece assim, que a vida vai parando".

Di Cavalcanti: "Hoje eu vou conversar com a nutricionista pra saber o que pode comer e não pode, porque aqui vem tudo certinho, né? Em casa é outro esquema. Tô morrendo de vontade de tomar um açaí bem grosso, mas não sei se pode".

A partir da análise dos discursos apresentados, percebeu-se que com a possibilidade do início do tratamento ambulatorial, já é possível pensar nas modificações da rotina individual e de suas famílias, assim como, nas possíveis reconfigurações nos papeis familiares e sociais após a alta hospitalar.

Conclui-se, nesta categoria, que o início do tratamento hemodialítico atrelado a longa internação hospitalar, se configura como um fator que contribuí para o sofrimento psíquico do paciente em dialise. A difícil transição a rotina da hemodiálise, unida a demora na espera pela vaga ambulatorial, podem estar relacionadas com a intensificação de queixas referentes a hospitalização, a inquietude e ao surgimento de sintomas psicológicos de ansiedade no aguardo de vaga ambulatorial e a intensificação de sintomatologia depressiva, principalmente quando o paciente percebe à ausência do suporte familiar e social.

\section{CONSIDERAÇÕES FINAIS}

Pode-se dizer que esta pesquisa foi o fechamento do ciclo de um percurso dentro do PRMS em atenção à saúde renal. Ressalta-se a relevância do acompanhamento psicológico durante o início do tratamento hemodialítico e após, no processo de internação, pois percebe-se que o diagnóstico que implica na entrada definitiva em diálise, é permeado por diversos sentimentos, com ênfase em períodos de tristeza e 
revolta. Em alguns casos, deixando o paciente mais vulnerável a desenvolver ansiedade e/ou uma tristeza profunda e persistente.

Percebeu-se que a inserção ao tratamento hemodialítico, frequentemente seguida pela hospitalização de média e longa duração, pelo diagnóstico indesejado e por mudanças de vida significativas e severas, ocasionadas pelo quadro clínico da doença, em suas consequências, preconceitos, estigmas e sofrimento intenso, é um processo complexo, que envolve diversos sentimentos, muitos deles conflitantes, e que evocam a necessidade de que o paciente entre em contato com seus recursos de enfrentamento, nem sempre existentes, desenvolvidos ou suficientes, para buscar passar por este momento com um pouco mais de serenidade.

\section{REFERÊNCIAS}

BASTOS, D. S. et al. Sintomas depressivos e suporte familiar em idosos e adultos em hemodiálise. Revista Psicologia: Teoria e Prática, São Paulo vol.18, n.2, pp. 103116, 2016. Disponível em < https://www.redalyc.org/pdf/1938/193848012008.pdf>. Acesso em 03, Jan 2020

CASTRO, R.V.R.S. et al. . A Percepção do Paciente Renal Crônico Sobre a Vivência em Hemodiálise. Revista de Enfermagem do Centro Oeste Mineiro, v. 8, 2018. Disponível em< http://www.seer.ufsj.edu.br/index.php/recom/article/view/2487>. Acesso em 23, nov. 2019

CAVALCANTE, V. C. M. Portadores de doença renal crônica em fase produtiva: percepção sobre limitações resultantes do adoecimento. Revista Médica de Minas Gerais, 2015. Disponível em < http://rmmg.org/artigo/detalhes/1861>. Acesso em: 18, Dez. 2019

COSTA, F.G. Rastreamento da depressão no contexto da insuficiência renal crônica. Temas em Psicologia, Ribeirão Preto. v. 22, n. 2, 2014.

COSTA, F. G.; COUTINHO, M.P.L. Hemodiálise e depressão: representação social dos pacientes. Psicol. estud., Maringá , v. 19, n. 4, p. 657-667, 2014 . Disponível 
em

<http://www.scielo.br/scielo.php?script=sci_arttext\&pid=S141373722014000400657\& Ing=en\&nrm=iso>. Acesso em 05 Jan. 2020.

FRAZAO, C. M. F. de Q. et al. Modificações corporais vivenciadas por pacientes com doença renal crônica em hemodiálise. Enferm. glob. v.15, n.43, pp.289-299, 2016. Disponível em < http://scielo.isciii.es/pdf/eg/v15n43/pt_administracion3.pdf>. Acesso em 14, dez. 2019.

KOVÁCS, M. J. Morte, separação, perdas e o processo de luto. In: KOVÁCS, M. J. (Org). Morte e desenvolvimento humano. 5 ed. São Paulo: Casa do Psicólogo, 2010.

KUBLER-ROSS, Elisabeth. Sobre a morte e o morrer. WMF Martins Fontes, 2019

NASCIMENTO, F. A. Uma contribuição às reflexões sobre os aspectos emocionais e o papel do psicólogo na Hemodiálise. Rev. SBPH, Rio de Janeiro v. 16, n. 1, p. 70-87,jun.2013.Disponível em <http://pepsic.bvsalud.org/scielo.php?script=sci_arttext\&pid=\$151608582013000100 005\&lng=pt\&nrm=iso $>$.Acesso em: 10 dez. 2019

OLIVEIRA, T. M. V. Amostragem não probabilística: adequação de situações para uso e limitações de amostras por conveniência, julgamento e quotas. Administração On Line: Prática, Pesquisa e Ensino. v. 2, n. 3, 2001.

OLIVEIRA S.G.; MARQUES I.R. Sentimentos do paciente portador de doença renal crônica sobre a autoimagem. Rev Enferm UNISA, 2011. Disponível em <https://docplayer.com.br/11054485-Sentimentos-do-paciente-portador-de-doencarenal-cronica-sobre-a-autoimagem.html>. Acesso em: 10 dez 1019.

PEREIRA, E. Et al. Escolha do método dialítico - variáveis clínicas e psicossociais relacionadas ao tratamento. Jornal Brasileiro de Nefrologia, São Paulo, v.38, n.2, p. 215-224. 2016. 
POP-JORDANOVA, N.; POLENAKOVIC, M. Personality profiles and depression in haemodyalisis patients. Prilozi,v.1, p117-129, 2012.

SILVA, A. S. et al. Percepções e mudanças na qualidade de vida de pacientes submetidos à hemodiálise. Rev. bras. enferm. v.64, n.5, p 839-844, 2011.

SILVA D.M.; SILVA R. M.C. R.A.; PEREIRA E.R. Alterações estéticas no contexto da doença renal crônica e complicações associadas à autoimagem. Revista Enfermagem Atual InDerme, v. 79, n. 17, 8 abr. 2016. Disponível em <https://revistaenfermagematual.com/index.php/revista/article/view/337> Acesso em: 15 dez. 2019.

SILVA A.L. et al. Perdas físicas e emocionais de pacientes renais crônicos durante o tratamento hemodialítico. Rev Brasil Saúde, 2014. v.2. p,52-65. Disponível em:<

http://www.seeradventista.com.br/ojs/index.php/RBSF/article/view/470>. Acesso em 07, Jan. 2019.

SILVA K.A.L. et al. Qualidade de vida de pacientes com insuficiência renal em tratamento hemodialítico. Rev enferm UFPE. V.11, 2017.

SOCIEDADE BRASILEIRA DE NEFROLOGIA. Censo 2018. Disponível em <: http:// www.censo-sbn.org.br/censosAnteriores>. Acesso em: 03 jan. 2020.

SOCIEDADE BRASILEIRA DE NEFROLOGIA. Compreendendo os rins. Disponível em: < sbn.org.br/publico/institucional/compreendendo-os-rins >. Acesso em: 25 de setembro de [2019].

SPINOLA, T.D.; GONÇALVES V.M.S. Percepção de pacientes com insuficiência renal crônica quanto a interferência da fístula arteriovenosa em seu cotidiano. Revista de Enfermagem Integrada, Ipatinga: Unileste, n.2, v, 5, Nov/Dez 2012. Disponível em<https://www.unileste.edu.br/enfermagemintegrada/artigo/v5_2/04percepcao-paciente-insuficiencia-renal-cronica-interferencia-fistula-arteriovenosacontidiano.pdf>. Acesso em: 10 dez. 2019. 
SZUSTER D.A.C et al. Sobrevida de pacientes em diálise no SUS no Brasil. Cad Saúde Pública, Rio de Janeiro, v. 28, p. 415-24, 2012.

TEIXEIRA, F.I.R et al. Sobrevida de pacientes em hemodiálise. Jornal Brasileiro de Nefrologia, São Paulo, v 37, n.1, p. 64-71, 2015.

Enviado: Fevereiro, 2020.

Aprovado: Outubro, 2020. 